\title{
A Collaborative e-Workspace for Digital Library of Malay Manuscripts
}

\author{
Zahidah Zulkifli, Member IACSIT
}

\begin{abstract}
Philology studies are often associated with traditional methods of teaching and learning. This study shows the best tools that can be implemented in order to make a collaborative work among Malay manuscripts community. The Soft System Methodology (SSM) is used to guide the investigation. The manuscript community comprises lecturers, students and researchers in the field of philology. Data were gathered from interviews, focus group discussions and observations. Academy of Malay Studies, University of Malaya is the case study setting, focusing on lecturers who teach and students who enrol in a philology course as well as doctoral students researching on manuscript studies. The findings highlight the features and modules that are available in the Malay manuscripts collaborative e-workspace in order to improve teaching, learning and researching as well as utilizing digitized manuscript surrogates held in a digital library of Malay manuscripts.
\end{abstract}

Index terms-Digital library, teaching and learning Malay manuscripts, collaborative workspace, soft system methodology.

\section{INTRODUCTION}

Digital Library of Malay Manuscript known as MyManuskrip (available at http://mymanuskrip.fsktm.um. edu.my) is a digital repository of handwritten Jawi script (adapted from Arabic alphabet) in Malay language. Malay manuscripts date as early as the 15 th century and represents the historical records of some 500 years of Malay historiography, laws of the Malay Sultanate, Malay governance, ancient foreign policy, folk sciences, medicine, religion, beliefs, Malay literature and culture, Malay rites and rituals, astrological and folk literature such as syair, gurindam, hikayat (Malay form of sonnets). MyManuskrip is a digitization initiative developed mainly to preserve, organise, and make manuscripts accessible through the web for researchers, scholars and public interested in reading, browsing or studying Malay Manuscripts. Currently, MyManuskrip provides users with options to browse and search a single collection or cross collections and provide university departments that offer courses on manuscript studies the use of e-manuscript collections for teaching and learning, especially in transliterating works [1]. However, currently, MyManuskrip does not include any services that support teaching, learning and researching activities, especially in much needed areas such as transliteration and annotation activities. Zainab [1] found that one of the problems faced by the manuscript teaching and learning

Manuscript received September 13, 2013; revised November 25, 2013.

Z. Zulkifli is with Kulliyyah of Information \& Communication Technology, International Islamic University Malaysia, Kuala Lumpur, Malaysia (e-mail: zahidahz@iium.edu.my). community is being unable to establish a dynamic collaborative platform amongst researchers and scholars or groups of manuscript studies students involved in joint transliteration work.

Hence, the objectives of this study are:

- To investigate what are the issues related to teaching, learning and researching in manuscript studies community.

- To propose a new environment as a solution that can support and improve the process of teaching, learning and researching in manuscript studies.

This study aims to improve the current practice in teaching, learning and researching Malay manuscripts utilizing resources provided by MyManuskrip (Digital Library of Malay Manuscripts) using the Soft System approach [2], [3].

\section{PRoJect InITIATIVES WORLDWIDE}

Digital libraries have grown from solely archiving digital materials to support other functions for their users such as being a platform for learning and research work. This progress can be seen in BAMBI or Better Access to Manuscripts and Browsing of Images initiative, which is an European digital archive of medieval manuscript collections [4]. BAMBI has been developed not only to provide a virtual platform for historians and philologists to browse and navigate the manuscripts in the collection but also provides a tool for philologists to write annotations, navigate between words of the transcription and match pieces of images in the numerated picture of the manuscript [5], [6]. BAMBI can be seen as a workspace that contains tools that support collaboration among users especially on the 'annotations on manuscript transcription' tool. It is available online and in CD-ROM. However, this system does not contain the manuscripts digitized collection and it is no longer accessible via Internet.

The Euro-Mediterranean Union framework of Medieval Medicine (EUMME) project, which is quite similar to BAMBI, is another example of manuscripts e-workspace that is focused on developing tools to help users to read the manuscript collections it holds [7]. The objectives are to increase the knowledge of the data relative to the subject treated, to increase linguistic knowledge and to develop technological tools specific for the study and dissemination of the information produced. EUMME only supports Arabic and Hebrew manuscripts and Medieval medicine scholars are the target users. EUMME also supports collaboration among users. This system supports the process of transcribe, annotate and index text presented in the images. However, this system is not accessible via Internet, it only can be used for specific users only, and like BAMBI, it has no 
manuscripts digitized collection.

Similarly, an E-learning System for Greek Paleography is an initiative to preserve antique documents and valuable manuscripts that focus on Greek Paleography of the Byzantine era and provides an interactive e-learning platform in order to value the collections in educational practices [7], [8]. In contains the Greek Paleography of the Byzantine era's collection. The objectives of this project are to preserve antique documents and valuable manuscripts and to provide an interactive E-learning platform in order to value collections in educational practices. It is supports the manuscripts specifically in Greek pearlscript type paleography of the 12th-19th century. This system is available via internet and also CD-ROM. This system also can only be used for specific users only which are Greek palaeographers.

The Bovary project, on the other hand, contains a collection of digitized manuscripts of Gustav Flaubert's manuscripts on Madam Bovary. This project initially started with collection of manuscripts without their transcriptions. It then progressed to include a text editor in order to help users to undertake transcription tasks more effectively and help to produce a structured textual representation adapted to users' requirements [9]. The objectives of this project are the digitization of a manuscript folder compound of almost 5,000 original manuscripts issued from "Madame Bovary" and to provide an hypertextual edition allowing an interactive and free Web access to materials. Unlike BAMBI and EUMME, Bovary contains the digitized manuscripts, which is the manuscript of Gustav Flaubert's on Madam Bovary [10]. Bovary includes a text editor that essentially provides an editing environment that integrates document analysis with interactive tools as well as making the original manuscripts collection available amongst researchers. However, it can be seen as a system with a lack of services since it is only offers the text editor, and in addition, it is no longer accessible via internet.

Most recently El-Makhfi and Benslimane [11] have proposed a platform for transcription and annotation of old Arabic manuscripts mainly to facilitate retrieval of the digitized collection. It proposed a new platform that facilitates transcription, establishment, of the old Arab handwritten in the form of annotations. The tools are focusing on the annotation which is textual annotations and graphical annotations. However, this is yet to be developed and it does not contain the manuscripts digitized collections.

From the initiative worldwide elaborated above, it can be seen that the limitations of the existing manuscripts e-workspaces are; supports only specific type of manuscripts, not accessible for public, lack of tools that supports collaboration among users and do not provide the manuscript collections.

\section{METHOdOLOGY}

Essentially, Soft System Methodology is a methodology that attempts to solve real world problems within the realm of the social system. Through SSM, a real-world problem situation can be investigated using a set of techniques. SSM's purpose is to investigate, understand and identify a problem.
SSM was chosen in this research because it can be used to analyse human activity systems and this study does involve itself with various human activity systems. In addition, it provides a model for enquiry which is easily understandable since the seven stages are laid out in a sequence which unfolds logically one after the other. One is able to investigate, understand and identify a problem or several problems present in a human activity system. It allows one to analyze a problem and take the necessary actions [12].

Fig. 1 shows how this research fits in to the SSM. However, this paper is focusing on the phase 3 of the SSM which is the stage 4 of SSM that called; constructing the conceptual model; how it can be done. It is to propose a conceptual framework of a new environment (as a solution) that can support and improve the process of teaching, learning and researching in manuscript studies.

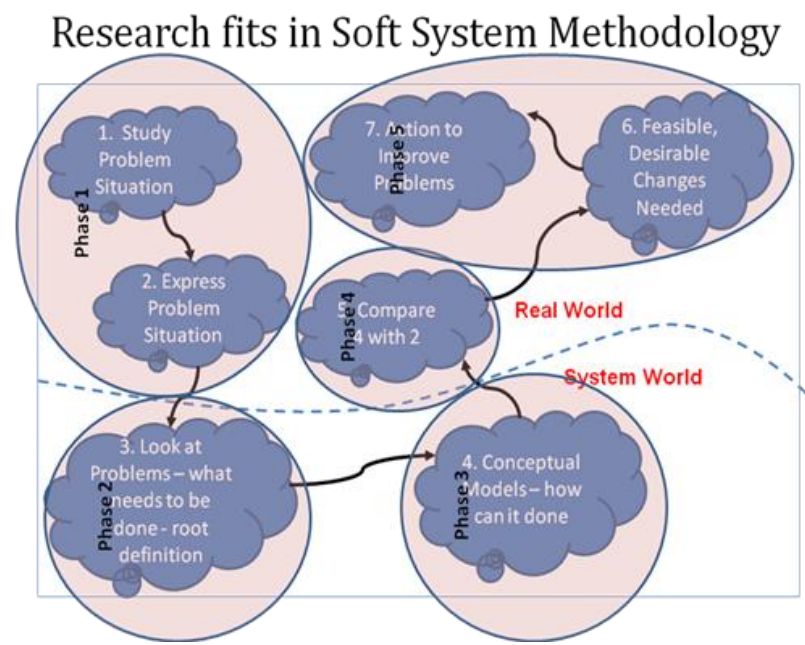

Fig. 1. How this research fits into the 7 steps of soft system methodology.

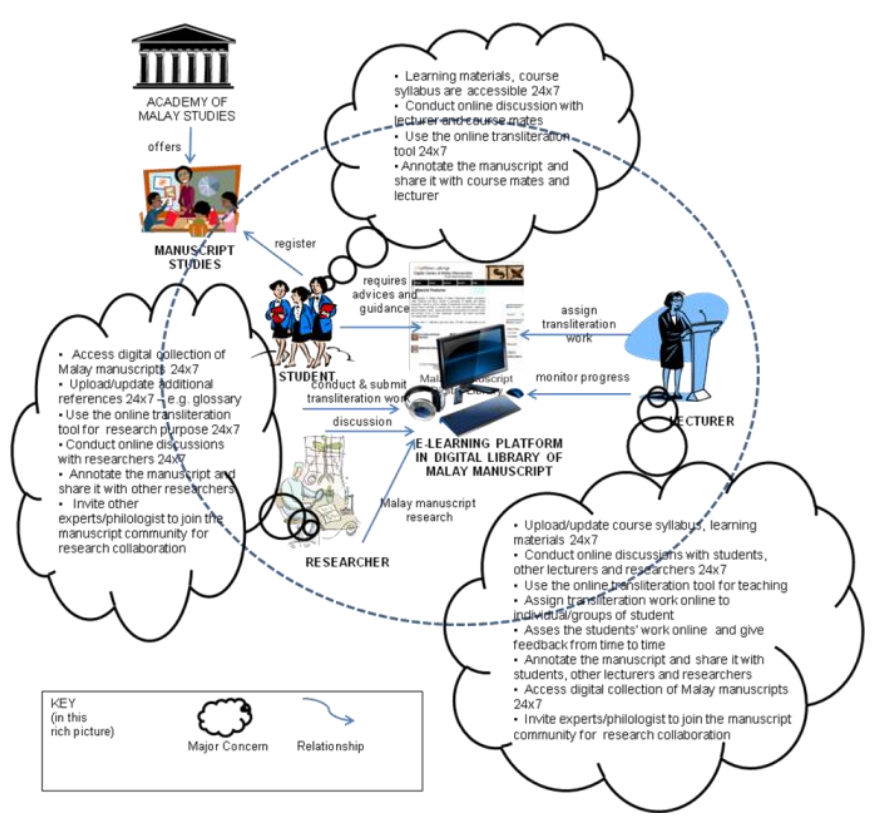

Fig. 2. Conceptual model representing the solution for problems.

In the previous report [13] shows the results from phase 1 and phase 2. Phase 1 was focusing on study the problem situation and expresses the problem situation. This study focuses on the Academy of Malay Studies, University of Malaya which is directly involved in teaching, learning and researching Malay manuscripts. In order to fully understand how the Malay manuscript users study Malay manuscripts, 
qualitative data has been collected by conducting series of interviews, focus groups and observations [14], [15]. The problem situation is then expressed using the rich pictures. After the problems had been identified, a conceptual model was developed in order to how various activities of different stakeholders in the current system are related to each other based on the root definition. The conceptual model demonstrates how technology can help solve the problems expressed by the Malay manuscript communities by mapping it to a proposed system as seen in Fig. 2.

\section{RESULTS AND DISCUSSIONS}

TABLE I: THE DESIGN IMPLICATIONS FROM THE THEMES

\begin{tabular}{|c|c|}
\hline Themes & Design Implications \\
\hline \multirow[t]{3}{*}{$\begin{array}{l}\text { Teaching } \\
\text { and } \\
\text { Learning } \\
\text { Manuscripts } \\
\text { Currently } \\
\text { Practiced }\end{array}$} & $\begin{array}{l}\text { The need of a collaborative workspace is which class } \\
\text { members can work together. Provide a function that can } \\
\text { invite others such as librarians to join the class in order } \\
\text { to provide references for students. } \\
\text { A module that provides transliteration process via } \\
\text { online, where students can discuss concurrently. } \\
\text { A workspace where lecturer can share documents such } \\
\text { as lecture notes and related article before and after } \\
\text { classes. } \\
\text { Various file sharing: a tool that can support file formats } \\
\text { such as .pdf, doc, ppt and .jpeg. } \\
\text { A text editor that can be updated by group members } \\
\text { within the time given. The text editor acts as a } \\
\text { 'Wikipedia'. }\end{array}$ \\
\hline & $\begin{array}{l}\text { The need of single Malay manuscript resources where } \\
\text { selected transliterations will be published in the } \\
\text { repository and this can promote Malay manuscripts to } \\
\text { others. }\end{array}$ \\
\hline & $\begin{array}{l}\text { The need to include report grading feature for lecturers. } \\
\text { Marks are automatically calculated and grades are } \\
\text { generated. }\end{array}$ \\
\hline \multirow[t]{3}{*}{$\begin{array}{l}\text { Supporting } \\
\text { Resources } \\
\text { for } \\
\text { Manuscript } \\
\text { Studies }\end{array}$} & $\begin{array}{l}\text { The need of a single resource of Malay manuscript } \\
\text { collections. This prevents duplication and redundant } \\
\text { works. } \\
\text { A module that compiles all students' assignments } \\
\text { (transliterated works) for future reference. The lecturer } \\
\text { can prevent the possibility of redundant works by } \\
\text { referring to the list of published works. }\end{array}$ \\
\hline & $\begin{array}{l}\text { The need of a communication module such as forums, } \\
\text { where discussions are made publicly, messaging, where } \\
\text { class members can communicate privately and open to } \\
\text { certain members by invitation; and chats, real time } \\
\text { messaging among the group members or public chats. }\end{array}$ \\
\hline & $\begin{array}{l}\text { The need of file sharing amongst lecturers and students. } \\
\text { Lecturers can upload electronic reference books for } \\
\text { students to refer. }\end{array}$ \\
\hline \multirow[t]{3}{*}{$\begin{array}{l}\text { Technology } \\
\text { Use and } \\
\text { Acceptance }\end{array}$} & $\begin{array}{l}\text { The need of personal workspace. Students can } \\
\text { customize their personal profile settings and make } \\
\text { them interesting according to their personal } \\
\text { preferences. Provide an individual file management } \\
\text { where students can upload and save all their works via } \\
\text { the system. } \\
\text { The need of an online Malay classical dictionary } \\
\text { where students can refer to them when it comes to } \\
\text { difficulties finding the meaning of a word during the } \\
\text { transliteration process. It will be updated by the } \\
\text { lecturer from time to tine according to needs. }\end{array}$ \\
\hline & $\begin{array}{l}\text { The need of a communication tool where students can } \\
\text { collaborate together. }\end{array}$ \\
\hline & $\begin{array}{l}\text { The need of module on collaboration works between } \\
\text { classes and between lecturers and students. Students do } \\
\text { not have to waste their time copying lecture notes while } \\
\text { the lecturer gives lectures. }\end{array}$ \\
\hline
\end{tabular}

The results from data collection from phase 1 and phase 2 (they have come out with a several themes) have a variety of implications for the design of content creation, tools and modules in the workspace, as well as the display format of the reports, as indicated in Table I. The design implications populated are expressed in the conceptual in Fig. 2.

Fig. 3 portrays the services in terms of data transforming processes, described exclusively in terms of the definition of the programme modules. The three system modules, namely, lecturer, students and researchers provide different access types for different levels of users, as presented in the following sub-sections. Along with this are specific definitions for security requirements, in terms of who (which role) has permitted access to which function. A detailed description of the digital library modules is described in the following sub-sections.

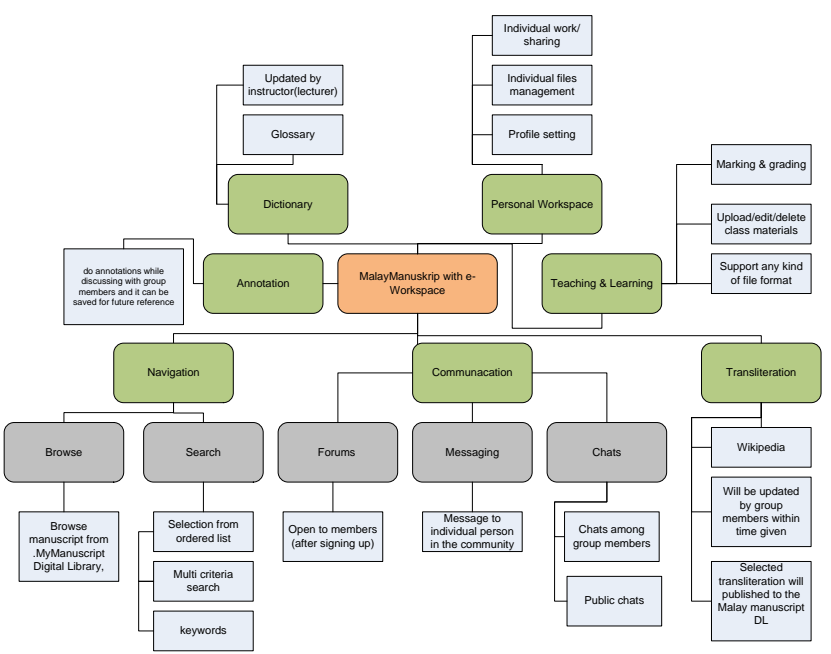

Fig. 3. Services in Malay manuscript e-workspace.

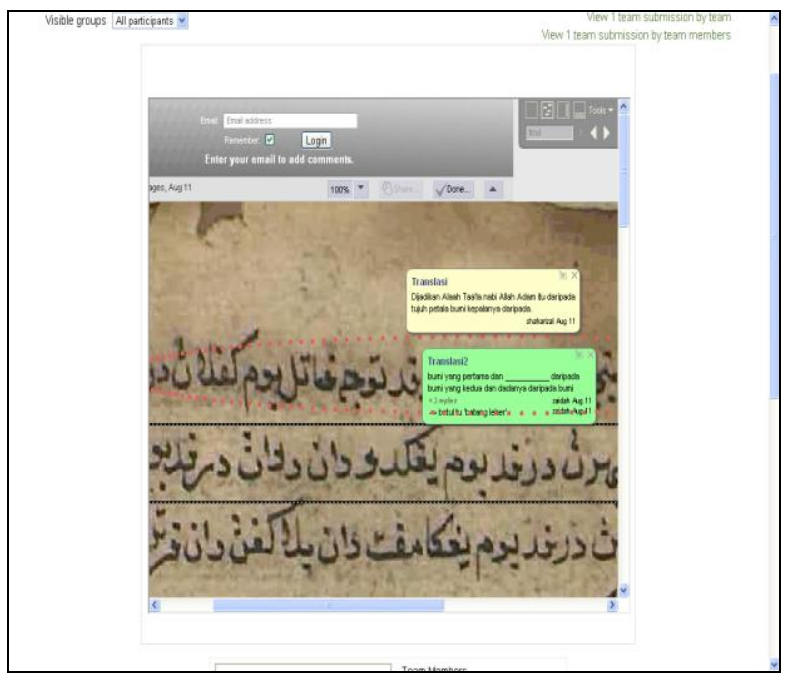

Fig. 4. Interface of annotation tool

Fig. 3 shows a list of modules that lecturers, students and researchers will be able to work within the Malay manuscript E-Workspace:

1) General functionality: This refers to the process performed by all users. After signing in, the users can set up their profiles and change user names and passwords. Group assignments can be carried out after creating a group. A function is provided where group members can be added, changed or removed. Guest ID will be given to those who are invited by lecturers or by request to the lecturers. Guest ID is normally given to experts in Malay manuscript studies as well as the public with interest on 
Malay manuscript research.

2) Annotation Tools: This is basically a text editor equipped with flexible tools that allows users to perform group assignments concurrently. Users are given options when utilizing this tool. They are given options such as plain notes, export, all notes, research trail and view. Fig. 4 shows one of the interface of annotation tool where users can do discussion together in real time.

3) MyManuskrip: This refers to the main repository for Malay manuscript collections. All assignments are given using these collections, which can prevent students from choosing the same manuscript for assignment purposes.

4) Document Delivery: Students organize, prepare and submit their project reports online. All documents such as lecture notes and assignments can be uploaded into user accounts and can be reached whenever needed. This system supports all types of document formats.

5) Working with Group Members: A leader needs to be chosen in order to create a group. Group discussion tools such as chatting, messaging and annotation are provided.

6) Working with Lecturers: Students can interact with lecturers via forums. Students may ask questions privately or make the question accessible to the public in order to obtain responses, especially if they have a vague idea on the information they are looking for or have difficulties in formulating specific queries. Students often consult their peers to obtain references at the early stage. User documentation is prominent throughout the system although the system should be rather easy to use by anyone familiar with the Internet.

7) Glossary: Lecturers index the project and other digital resources to make the contents searchable and available to be used by students and other users. The idea was taken from a previous project that called 'Jawi-Malay Transliteration' [16] that acts like an online dictionary.

8) Transliteration Tool: This is also a text editor, but it will be used in the final stage of the assignment. This produces a clean version of transliterated work.

9) Searching: Students in general perform searching (seek specific information) or browsing (navigate, whereby they expect to find topics available wherein some are useful information). These two features have to be supported by the E-Workspace. This means that students should be able to search and browse graded project reports from previous years. The system is browseable by collection types to inform students what is available on the topics. Students and lecturers should be able to perform simple search through a Google-type box for free-text searching although an advanced search would be desirable. The survey finds that the students are very familiar with Google, they employ a few search terms, rarely modify their queries, and rarely use advanced search features. The results are presented in a clean manner with a brief description of the digital content.

10) Submission and Grading System: The lecturers check the students' progress from time to time and keep track of students who have begun documenting their projects and those who have not. The lecturers evaluate and grade their students' projects online, and communicate the grades to students once the assignments are evaluated.

\section{CONCLUSION}

The Malay manuscript E-Workspace consists of ten modules which offer a digital platform to facilitate teaching, learning and researching manuscripts activities among paleographers. Further research will be discussing on next phase of SSM which include comparing the conceptual model to the current problem situation (the manuscript studies), identifying changes that should be made and making improvements. In conclusion, the provision of an online platform to support the teaching, learning and research activities together with the use of resources from MyManuskrip, is generally welcomed by philology lecturers, students and researchers at the Academy of Malay Studies, University of Malaya. Specifically, the modules can support transliteration and annotation activities, use current digital manuscript resources from MyManuskrip, allow lecturers to upload their syllabus and teaching resources, support interactivity in terms of student-lecturer, student-student discussions; the uploading of transliterated assignments as a collection in MyManuskrip; and the provision of a dictionary of terms to assist manuscript researchers. Generally, the system is able to support discussions and the sharing of knowledge while promoting Malay Manuscript widely. The E-Workspace emphasizes on collaborative resource development and knowledge sharing. There are very few local resources or similar systems in Malaysia that can be located and used as reference [17]. It is hoped that this study will "jumpstart" other studies related to various aspects of Malay manuscript studies.

\section{ACKNOWLEDGMENT}

My deepest thanks to my supervisor, Dr Noorhidawati Abdullah, the guide of this research. To Prof Zainab Awang Ngah, who I am extremely grateful and indebted to her for her expert, sincere, and valuable guidance and encouragement extended to me. Without their knowledge this thesis would have been not possible. To University of Malaya as the place during my $\mathrm{PhD}$ study, and to International Islamic University Malaysia who are the current institution that I am working with.

\section{REFERENCES}

[1] A. N. Zainab, A. Abrizah, and M. R. Hilmi, "What a digital library of Malay manuscripts should support an exploratory needs analysis," Libri, vol. 59, no. 4, pp. 275-289, 2009.

[2] M. R. M. Hilmi and A. N. Zainab, "Creating a digital library to handle Malay manuscripts using Greenstone," in Proc. ICOLIS 2007, 2007, Kuala Lumpur, pp. 223-231

[3] M. R. M. Hilmi, "The organization and access to digitized Malay manuscripts: creating a digital library using Greenstone," Dissertation (MLIS), Faculty of Computer Science and Information Technology University of Malaya, 2009.

[4] B. Rumpler and S. Calabretto, "Virtual Library for Ancient Manuscripts," Library Review, Emerald, vol. 48, 181-187, 1999.

[5] A. Bozzi and S. Calabretto, "The digital library and computational philology: the BAMBI project," Research and Advanced Technology for Digital Libraries, vol. 1324, pp. 269-285, 1997.

[6] S. Calabretto and A. Bozzi, "The philological workstation BAMBI (Better access to manuscripts and browsing of Images)," Journal of Digital Information, vol. 1, no. 3, 1998

[7] A. Bozzi, M. S. Corradini, and B. Tellez, "The EUMME Project: towards a new philological workstation," presented at ELPUB2005 Conference on Electronic Publishing, 2005 
[8] A. S. Drigas, A. T. P. Kyragianni, P. Nikolopoulos, D. Kalomoirakis, S Peradonis, D. Kouremenos, C. H. Emmanouilidis, and J. Vrettaros, "An e-learning platform for multiform and interactive education of scholars in Greek Paleography," presented at WSEAS Conference, 2005.

[9] S. Nicholas, T. Paquet, and L. Heutte, "Digitizing Cultural Heritage Manuscripts: the Bovary Project," ACM Symposium on Document Engineering, 2003, Grenoble, France, pp. 55-57.

[10] S. Nicholar, T. Paquet, and L. Heutte, "Enriching historical manuscripts: The Bovary Project," Document Analysis Systems 6, Lecture Notes in Computer Science, vol. 3163, pp. 135-146, 2004.

[11] N. E. Makhfi and R. Benslimane, "Platform of Transcription the Old Arabic Manuscripts," International Journal of Engineering Science and Technology, vol. 3, no. 6, pp. 5353-5365, 2011.

[12] C. N. N. Edzan, "Modeling an Information Literacy Programme for Undergraduates: A Soft Systems Methodology Approach," PhD diss. Faculty of Computer Science and Information Technology, University of Malaya, Malaysia, 2007

[13] Z. Zahidah, A. Noorhidawati, and A. N. Zainab, "Exploring the needs of Malay manuscripts teaching and learning community for an e-learning platform," Malaysian Journal of Library \& Information Science, vol. 16, no. 3, pp. 31-47, 2011.

[14] J. W. Cresswell, Research Design Qualitative, Quantitative and Mixed Methods Approaches, 2003, Sage Publication.
[15] B. Hancock, Trent Focus for Research and Development in Primary Health Care: An Introduction to Qualitative Research, 2002.

[16] R. A. Ghani, M. S. Zakaria, and K. Omar, Jawi-Malay Transliteration, New York, 2009.

[17] A. M. Zuraidah, "Establishing the national digital cultural heritage repository in Malaysia," Library Review, Emerald, vol. 57, pp. 537-2535, 2008.

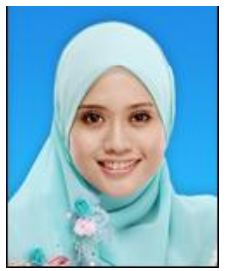

Zahidah Zulkifli is currently an assistant professor at the Department of Information System in the Kulliyyah of Inforamtion \& Communication Technology, International Islamic University Malaysia. She graduated with BSC (Bachelor of Science Computer) in 2006 and Masters of Science (IT Management) in 2007 both from Universiti Technology Malaysia.

Dr. Zahidah obtained her $\mathrm{PhD}$ in 2013 from University of Malaya. Her research interests include digital library, information management, information system and distance learning education. This author became a Member (M) of IACSIT. 